\title{
Quantification of some ornamental plant species carbon dioxide absorption for various moisture conditions
}

\author{
Svetlana Korsakova*, Yuri Plugatar, and Maksim Kovalev \\ The Nikitsky Botanical Gardens - National Scientific Center of the RAS, 298648 Nikita, Yalta, \\ Russian Federation
}

\begin{abstract}
The study of carbon dioxide gas exchange of leaves of Prunus laurocerasus L., Laurus nobilis L. and Viburnum tinus L. under various environmental conditions was carried out. The greatest resistance to drought and the ability to absorb $\mathrm{CO}_{2}$ under hydrothermal stress was found in Viburnum tinus plants. It was determined that the inhibition of the processes of $\mathrm{CO}_{2}$ absorption with increasing water scarcity begins in the studied species with a decrease in soil moisture to $35 \%$ field capacity. Under conditions of soil drought, the amount of $\mathrm{CO}_{2}$ absorbed by Prunus laurocerasus leaves is reduced by 10 times, Laurus nobilis - by 7 times, Viburnum tinus - by 2 times. The positive carbon dioxide gas exchange of Prunus laurocerasus, Laurus nobilis and Viburnum tinus in the hot dry period, when the amount of $\mathrm{CO}_{2}$ absorption exceeds its release during respiration by $1-5.1,1.5-3.7$ and $1.1-6.2$ times, respectively, indicates a significant potential these species for optimizing the urban ecosystems of the southern regions of Russia. The developed predictive models allow us to perform a quantitative assessment of the ability of plants to absorb carbon dioxide under various environmental conditions.
\end{abstract}

\section{Introduction}

In the modern world, where the urbanized territories are experiencing a deterioration of the environmental conditions, largely due to the increase in the level of man-made load, the importance of green spaces becomes significant, and woody plants play here the leading role $[1,2]$. Green spaces provide important ecosystem services: reduce pollution of air and water basins, regulate the microclimate, creating shade and cooling effect in the hot season $[3,4]$. They are of recreational and cultural value, reduce the amount of ultraviolet radiation, absorb carbon dioxide, produce oxygen, etc. [5-7].

Due to the increase in the concentration of $\mathrm{CO}_{2}$ and other greenhouse gases in the atmosphere, which are a key factor in climate change and global warming, the study of all components of the carbon balance in the biosphere is of particular relevance [6]. A significant reduction in $\mathrm{CO}_{2}$ emissions in urban ecosystems will be facilitated by the

\footnotetext{
* Corresponding author: korsakova2002@mail.ru
} 
effective selection of woody plants that comprise the bulk of the biomass of green spaces. Woody plants affect the level of carbon dioxide in the atmosphere by absorbing it through photosynthesis and depositing it in phytomass, as well as releasing carbon dioxide back into the atmosphere during respiration and as a result of vegetation decomposition [7]. However, plant species may have different mechanisms of adaptation to the environment, so their leaf absorption of $\mathrm{CO}_{2}$ differs [8]. In this regard, when selecting woody plant species for use in urban ecosystem plantings, it is very important to take into account their participation in the carbon balance of the atmosphere. The selection of species that are most resistant to the environment for use in landscape architecture and planted forests with different levels of water availability will have a positive impact on air quality and climate change.

Studying the species-specific response of woody plants to environmental conditions will improve our understanding of how and to what extent different species reduce $\mathrm{CO}_{2}$ concentrations during photosynthesis. This is necessary for effective planning and management of green spaces in order to optimize land use in urbanized areas.

However, today, these issues are not fully reflected in existing publications. Also, a small number of works are devoted to the construction of ecophysiological models based on round-the-clock synchronous registration of changes in plant carbon dioxide gas exchange and environmental parameters [9]. In most studies, when developing ecophysiological models, the dependence of photosynthesis on three environmental factors is analyzed: the intensity of photosynthetically active radiation, air temperature, and vapor pressure deficit [10]. The influence of water and temperature conditions of the soil is rarely taken into account [11].

As a rule introduced species play key role in increasing the aesthetic and functional value of green spaces in urbanized ecosystems. Considering the expected rise temperatures and increase duration of droughts in the southern regions of Russia, according to climate change scenarios [12], plants should have sufficient plasticity to adapt to these new environmental conditions. This determines the relevance of research on the ability of tree introduced species to absorb carbon dioxide under various conditions of moisture availability. The results of such studies allow us to assess the contribution of each plant or its species to the carbon balance of the atmosphere under conditions intensification of rising temperature and climate aridization.

The objective of this study was to determine the quantitative indicators of daily carbon dioxide absorption and the regularities of the species-specific photosynthetic responses of Prunus laurocerasus L., Laurus nobilis L. and Viburnum tinus L. on the impact of the environmental condition during their growing season.

\section{Materials and methods}

Studies of photosynthetic and respiratory activity of tree introduced species were conducted on the Southern Coast of the Crimea (SCC) on the territory of the Nikitsky Botanical Gardens - National Scientific Center of the RAS ( $\left.44^{\circ} 31^{\prime} \mathrm{N}, 34^{\circ} 15^{\prime} \mathrm{E}\right)$.

The climate of the SCC is subtropical of the Mediterranean type, with moderately humid winters, hot and dry summers. The long-term (1930-2015) average annual air temperature is $12.6{ }^{\circ} \mathrm{C}$; the absolute maximum in summer reached $39{ }^{\circ} \mathrm{C}$, the absolute minimum in winter dropped to $-14.6{ }^{\circ} \mathrm{C}$; the average annual precipitation is $592 \mathrm{~mm}$ [9].

The objects of research were seedlings (4-6 years old) of three valuable species of evergreen ornamental woody introducers: common laurel cherry (Prunus laurocerasus L.), bay tree (Laurus nobilis L.) and laurestinus viburnum (Viburnum tinus L.). These plant species are widely distributed in the landscaping in the SCC, the Black Sea coast of the Caucasus, and the Mediterranean region [13]. 
The studies were carried out during the active vegetation period from June to October (in 2016 and 2020) on plants growing in the experimental site and under conditions of the growing experience (in 15-liter vegetation vessels filled with the soil of the experimental site). The soil of the experimental site is dark brown, medium clay, the field capacity (FC) ranges from 21.6 to $25.2 \%$, the wilting point is $9.9-11.1 \%$.

When studying the effect of hydrothermal stressors on the processes of leaf gas exchange, the plants were exposed to environmental conditions that simulate the hot summer of the Southern Coast of the Crimea and the conditions of soil water deficit. The soil moisture in the vessels with the control plants was maintained at a level corresponding to the moisture content of $60-90 \%$ FC.

The intensity of $\mathrm{CO}_{2} / \mathrm{H}_{2} \mathrm{O}$ gas exchange was determined in three replications on welldeveloped intact leaves of the upper part of the shoot, with an interval of 20 minutes (72 measurements per day). The environmental parameters were recorded synchronously with the gas exchange measurements. The measurements were performed using the PM-11z phytomonitor and the open-type automatic 4-channel system for monitoring $\mathrm{CO}_{2}$ gas exchange and leaf transpiration "PTM-48A Photosynthesis Monitor", specially designed for long-term monitoring of the carbon dioxide exchange of several leaves simultaneously (Bioinstruments S.R.L., Moldova) [9]. The technology includes the measurement of three main processes: visible photosynthesis (absorption of $\mathrm{CO}_{2}$ by the leaf), photorespiration, and dark respiration. Self-closing leaf chambers of the original design practically do not affect the life conditions of the leaf, which is fundamentally important for long-term measurements.

To calculate the amount of photosynthetically active radiation (PAR) that the plant receives during the daylight hours, Daily Light Integral (DLI) is used. DLI is a function of photosynthetic light intensity and duration (day length) and is usually expressed as moles of light (mol photons) per square meter $\left(\mathrm{m}^{-2}\right)$ per day $\left(\mathrm{d}^{-1}\right)$, i.e. $\mathrm{mol} \mathrm{m}^{-2} \mathrm{~d}^{-1}[14]$.

The statistically distributed model of multiple nonlinear regression was built on the platform of the Statistica 10 package based on the initial sample, in which environmental factors were considered as independent variables. To find the regression coefficients, we used step-by-step regression analysis and the "Nonlinear estimation" procedure of the "User regression - derived function of the loss" module. The Quasi-Newton method for minimizing the loss function was chosen as the estimation procedure. The adequacy of the constructed model was evaluated by the values of the "Total losses" statistics. The smaller the values of the statistics, the more adequate the model is. The model includes indicators for which the significance level of the Student's $p$ criterion is not more than 0.05 .

Estimated of the approximation accuracy and the best models were determined based on three performance indicators: the coefficient of determination $\left(\mathrm{R}^{2}\right)$, Root Mean Squared Error (RMSE), and error sum of squares (SSE). The equations with the highest $\mathrm{R}^{2}$ and the lowest RMSE and SSE were chosen as the most suitable models [8].

The resulting of dataset was analyzed taking information and mathematical criteria in MS Excel 2010 and Statistica 10 application software. All calculations were performed at a given significance level $p<0.05$.

\section{Results and Discussion}

Table 1 shows the average daily, maximum and minimum values of environmental parameters and leaf $\mathrm{CO}_{2} / \mathrm{H}_{2} \mathrm{O}$ gas exchange during the all measurement period from June to October, reflecting seasonal fluctuations in environmental conditions and the speciesspecific functioning of the assimilation apparatus in these habitat conditions: Prunus laurocerasus - for 35 days, Laurus nobilis - for 75 days and Viburnum tinus - for 59 days. The analysis of the data showed that, on average, during the growing season, 
Prunus laurocerasus is characterized by the highest carbon dioxide absorption capacity per unit of leaf surface of the analyzed plant species, and Viburnum tinus is characterized by the highest transpiration intensity. Under the favorable environmental conditions, the amount of $\mathrm{CO}_{2}$ absorbed per unit area of the leaf surface of Viburnum tinus was 1.5 times higher than that of Prunus laurocerasus and Laurus nobilis. When effect of strong hydrothermal stress on plants the absorption of carbon dioxide by Viburnum tinus leaves decreased in comparison with the control (no stressors) by 6-8 times. At the same time, the amount of $\mathrm{CO}_{2}$ absorbed by Viburnum tinus leaves under severe drought conditions was 2 times higher than by Prunus laurocerasus leaves, and Laurus nobilis had a negative carbon balance between the level of $\mathrm{CO}_{2}$ assimilation during photosynthesis and its loss during respiration (Table 1). Differences in the photosynthetic activity of the studied species under optimal and stressful conditions were statistically significant with a $95 \%$ probability.

Table 1. Parameter values of environment and $\mathrm{CO}_{2} / \mathrm{H}_{2} \mathrm{O}$ gas exchanges in leaves of evergreen plants during measurement.

\begin{tabular}{|c|c|c|c|c|c|c|}
\hline \multirow{2}{*}{ Parameter } & \multicolumn{2}{|c|}{ Prunus laurocerasus } & \multicolumn{2}{|c|}{ Laurus nobilis } & \multicolumn{2}{|c|}{ Viburnum tinus } \\
\hline & Min / Max & Average & Min / Max & Average & Min / Max & Average \\
\hline $\mathrm{E}\left(\mathrm{mgH}_{2} \mathrm{O} \mathrm{cm}^{-2} \mathrm{~d}^{-1}\right)$ & $4.9 / 234.7$ & $104.5 \pm 55.1$ & $11.8 / 259.5$ & $97.2 \pm 53.5$ & $15.6 / 353.3$ & $119.8 \pm 82.3$ \\
\hline $\mathrm{g}_{\mathrm{S}}\left(\mathrm{mm} \mathrm{s}^{-1}\right)$ & $0.27 / 1.50$ & $0.93 \pm 0.35$ & $0.10 / 1.59$ & $0.88 \pm 0.38$ & $0.25 / 3.80$ & $1.33 \pm 0.70$ \\
\hline $\mathrm{A}\left(\mathrm{mgCO}_{2} \mathrm{~cm}^{-2} \mathrm{~d}^{-1}\right)$ & $0.08 / 1.63$ & $1.03 \pm 0.43$ & $-0.05 / 1.63$ & $0.84 \pm 0.42$ & $0.15 / 2.23$ & $0.95 \pm 0.39$ \\
\hline $\mathrm{R}_{\mathrm{RTotal}}\left(\mathrm{mgCO}_{2} \mathrm{~cm}^{-2} \mathrm{~d}^{-1}\right)$ & $0.20 / 0.97$ & $0.55 \pm 0.24$ & $0.10 / 0.73$ & $0.36 \pm 0.16$ & $0.15 / 0.97$ & $0.34 \pm 0.22$ \\
\hline $\mathrm{R}_{\mathrm{RD}}\left(\mathrm{mgCO} \mathrm{cm}^{-2} \mathrm{~d}^{-1}\right)$ & $0.12 / 0.75$ & $0.43 \pm 0.22$ & $0.03 / 0.56$ & $0.18 \pm 0.12$ & $0.10 / 0.74$ & $0.24 \pm 0.17$ \\
\hline $\mathrm{R}_{\mathrm{PR}}\left(\mathrm{mgCO} \mathrm{cm}^{-2} \mathrm{~d}^{-1}\right)$ & $0.04 / 0.24$ & $0.12 \pm 0.05$ & $0.07 / 0.53$ & $0.18 \pm 0.10$ & $0.03 / 0.24$ & $0.11 \pm 0.05$ \\
\hline $\operatorname{DLI}\left(\mathrm{mol} \mathrm{m}^{-2} \mathrm{~d}^{-1}\right)$ & $0.6 / 48.2$ & $24.1 \pm 11.9$ & $5.8 / 41.7$ & $21.2 \pm 8.3$ & $0.9 / 30.8$ & $15.8 \pm 8.4$ \\
\hline $\mathrm{T}\left({ }^{\circ} \mathrm{C}\right)$ & $15.0 / 31.2$ & $23.7 \pm 4.9$ & $8.5 / 33.8$ & $24.2 \pm 5.2$ & $16.9 / 31.6$ & $22.0 \pm 4.6$ \\
\hline $\mathrm{T}_{\operatorname{MAX}}\left({ }^{\circ} \mathrm{C}\right)$ & $17.0 / 39.7$ & $31.4 \pm 5.6$ & $12.9 / 41.5$ & $32.3 \pm 5.5$ & $19.1 / 41.8$ & $30.3 \pm 5.6$ \\
\hline $\mathrm{T}_{\mathrm{MIN}}\left({ }^{\circ} \mathrm{C}\right)$ & $11.4 / 25.2$ & $18.4 \pm 4.2$ & $4.5 / 28.4$ & $18.5 \pm 5.3$ & $12.0 / 26.9$ & $17.1 \pm 4.5$ \\
\hline RH (\%) & $49.2 / 82.4$ & $65.9 \pm 10.4$ & $38.7 / 77.8$ & $56.1 \pm 9.4$ & $42.5 / 79.3$ & $58.1 \pm 9.7$ \\
\hline $\mathrm{VPD}(\mathrm{kPa})$ & $0.30 / 2.40$ & $1.21 \pm 0.63$ & $0.40 / 3.31$ & $1.54 \pm 0.66$ & $0.40 / 2.84$ & $1.29 \pm 0.64$ \\
\hline SM (\% FC) & $24.8 / 97.0$ & $73.9 \pm 17.7$ & $10.8 / 95.9$ & $61.3 \pm 19.5$ & $14.8 / 97.5$ & $66.4 \pm 24.5$ \\
\hline \multicolumn{7}{|c|}{$\begin{array}{l}\mathrm{E} \text { - average daily transpiration; } \mathrm{g}_{\mathrm{S}}-\text { stomatal conductance; } \mathrm{A}-\text { average daily carbon dioxide absorption; } \\
\mathrm{R}_{\mathrm{RTotal}} \text { - total carbon dioxide release due to the respiration; } \mathrm{R}_{\mathrm{RD}}-\text { carbon dioxide release due to the dark } \\
\text { respiration; } \mathrm{R}_{\mathrm{PR}}-\text { carbon dioxide release due to the photorespiration; } \mathrm{DLI}-\mathrm{Daily} \text { Light Integral; } \mathrm{T}-\text { average } \\
\text { daily air temperature; } \mathrm{T}_{\mathrm{MAX}} \text { - daily maximum air temperature; } \mathrm{T}_{\mathrm{MIN}} \text { - daily minimum air temperature; } \mathrm{RH} \text { - } \\
\text { average daily relative humidity; VPD - vapor pressure deficit; } \mathrm{SM} \text { - soil moisture; } \pm \text { - standard deviation. }\end{array}$} \\
\hline
\end{tabular}

During the active growing season from June to October, the maximum average daily amount of $\mathrm{CO}_{2}$ absorbed per unit area of the Prunus laurocerasus leaf blade was observed in June $\left(1.38 \mathrm{mgCO}_{2} \mathrm{~cm}^{-2} \mathrm{~d}^{-1}\right)$ and in September $\left(1.30 \mathrm{mgCO}_{2} \mathrm{~cm}^{-2} \mathrm{~d}^{-1}\right)$. In July and October, the daily absorption of $\mathrm{CO}_{2}$ remained at the level of $0.72-0.73 \mathrm{mgCO}_{2} \mathrm{~cm}^{-2} \mathrm{~d}^{-1}$ (Fig. 1). The maximum release of carbon dioxide back into the atmosphere during respiration of $0.83 \mathrm{mgCO}_{2} \mathrm{~cm}^{-2} \mathrm{~d}^{-1}$ was observed in July. The seasonal dynamics absorption of carbon dioxide by the leaves of Laurus nobilis showed slight fluctuations $\left(0.78-0.86 \mathrm{mgCO}_{2} \mathrm{~cm}^{-2} \mathrm{~d}^{-1}\right)$ with a maximum in July $\left(0.93 \mathrm{mgCO}_{2} \mathrm{~cm}^{-2} \mathrm{~d}^{-1}\right)$. The maximum release of $\mathrm{CO}_{2}$ during respiration was observed in June $\left(0.53 \mathrm{mgCO}_{2} \mathrm{~cm}^{-2} \mathrm{~d}^{-1}\right)$ during the period of active leaf growth. The maximum average daily absorption of carbon dioxide by Viburnum tinus leaves was in August $\left(1.17 \mathrm{mgCO}_{2} \mathrm{~cm}^{-2} \mathrm{~d}^{-1}\right)$, and the release was in June $\left(0.80 \mathrm{mgCO}_{2} \mathrm{~cm}^{-2} \mathrm{~d}^{-1}\right)$. A decrease in assimilation activity in October was natural for all species with the attenuation of growth processes (Fig. 1).

The calculation of the share of total respiratory costs from gross-photosynthesis $\left(\sum\left(R_{R D}+R_{P R}\right) /\left(A+R_{R D}+R_{P R}\right)\right)$ and the analysis of the seasonal dynamics the main processes of carbon dioxide exchange in leaves (absorption and release of $\mathrm{CO}_{2}$ ) showed that in the hot summer months, the analyzed evergreen plant species spend a fairly high amount of photoassimilates on respiration. The share of respiratory costs in June - August in Prunus laurocerasus averages 27.6-53.5\%, in Laurus nobilis - 30.7-40.6\%, in 
Viburnum tinus in June 47.9\%, and in July - August ranges from 14-26\%. According to our data, under optimal environmental conditions, the ratios processes of respiration and photosynthesis in introduced plants are on average 21.9\% (Prunus laurocerasus), $12.8 \%$ (Laurus nobilis) and 12.0\% (Viburnum tinus) [15].

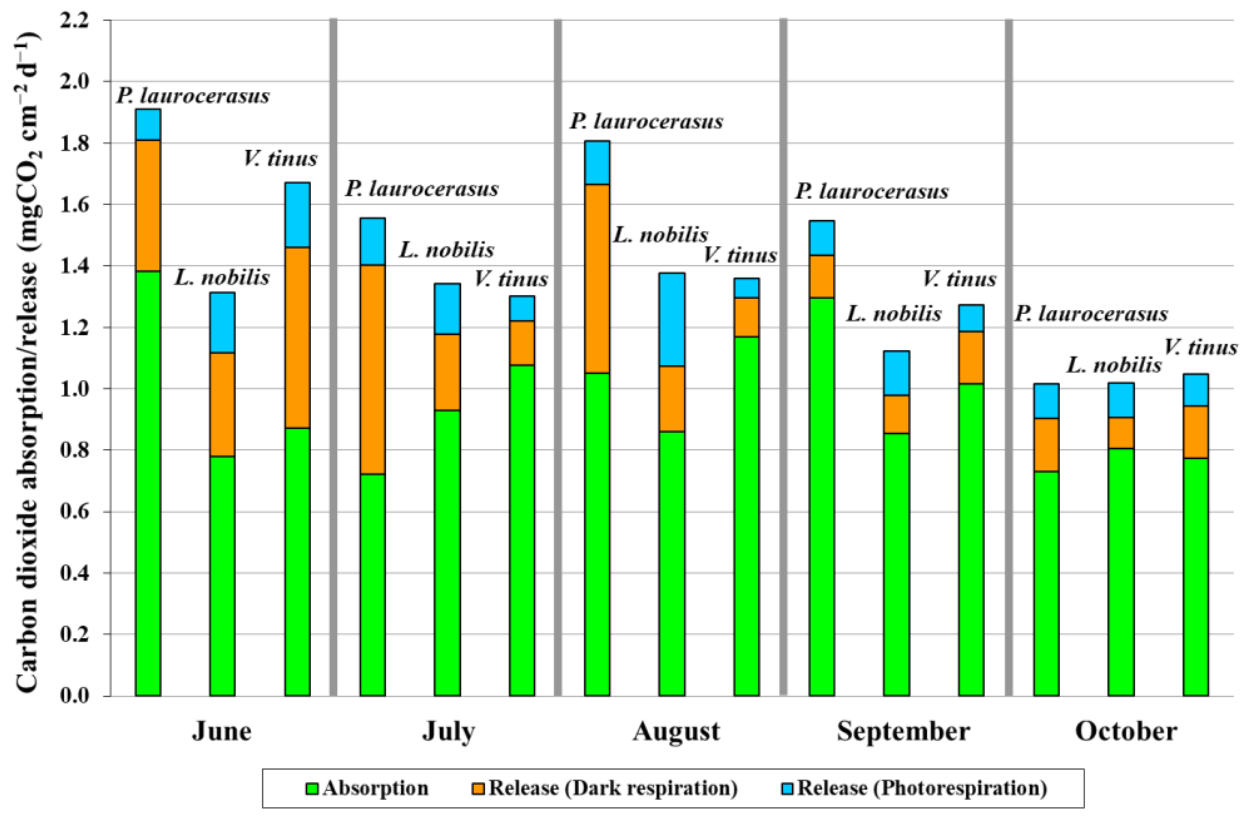

Fig. 1. Dynamics of daily carbon dioxide absorption/release by Prunus laurocerasus, Laurus nobilis and Viburnum tinus leaves during vegetation.

Analysis of calculations under conditions of increasing soil-moisture deficit showed that the intensity of $\mathrm{CO}_{2}$ absorption per unit area of the leaf blade of experimental plants began to decrease at soil moisture below 30-35\% FC (Fig. 2). With a decrease in soil moisture to $30 \%$ FC or less, species-specific features of the plant response to drought and regulation of the water balance were revealed. The amount of $\mathrm{CO}_{2}$ absorbed by leaves decreased by 10 times in comparison with the conditions of sufficient water supply in Prunus laurocerasus, 7 times in Laurus nobilis, and only 2 times in Viburnum tinus. In current conditions of water availability with a low growth of dark respiration rate in Laurus nobilis and Viburnum tinus, its share in the process of carbon dioxide gas exchange in Prunus laurocerasus increased by 2 times. The increase of total respiration rate under conditions of water deficit is obviously due to the fact that in parallel with the decrease in growth processes, the intensity of maintenance respiration increases due to the adaptive component against the background of a decrease in the intensity of growth respiration and gross-photosynthesis.

Our previous studies [15] revealed three types of responses to water deficiency in these species of woody plants. The plants of Laurus nobilis are characterized by a droughtresistant type the regulation of water balance by closing the stomata, Prunus laurocerasus is characterized by a productive type the preservation of water balance in the plant by maintaining a high level of transpiration, and Viburnum tinus has a combined type of response. In the third type of response, stomata were kept open at the first stage of the physiological response to water stress and closed at the second stage due to insufficient water delivery from the roots. This plasticity provides Viburnum tinus plants with a high adaptive capacity to drought. 


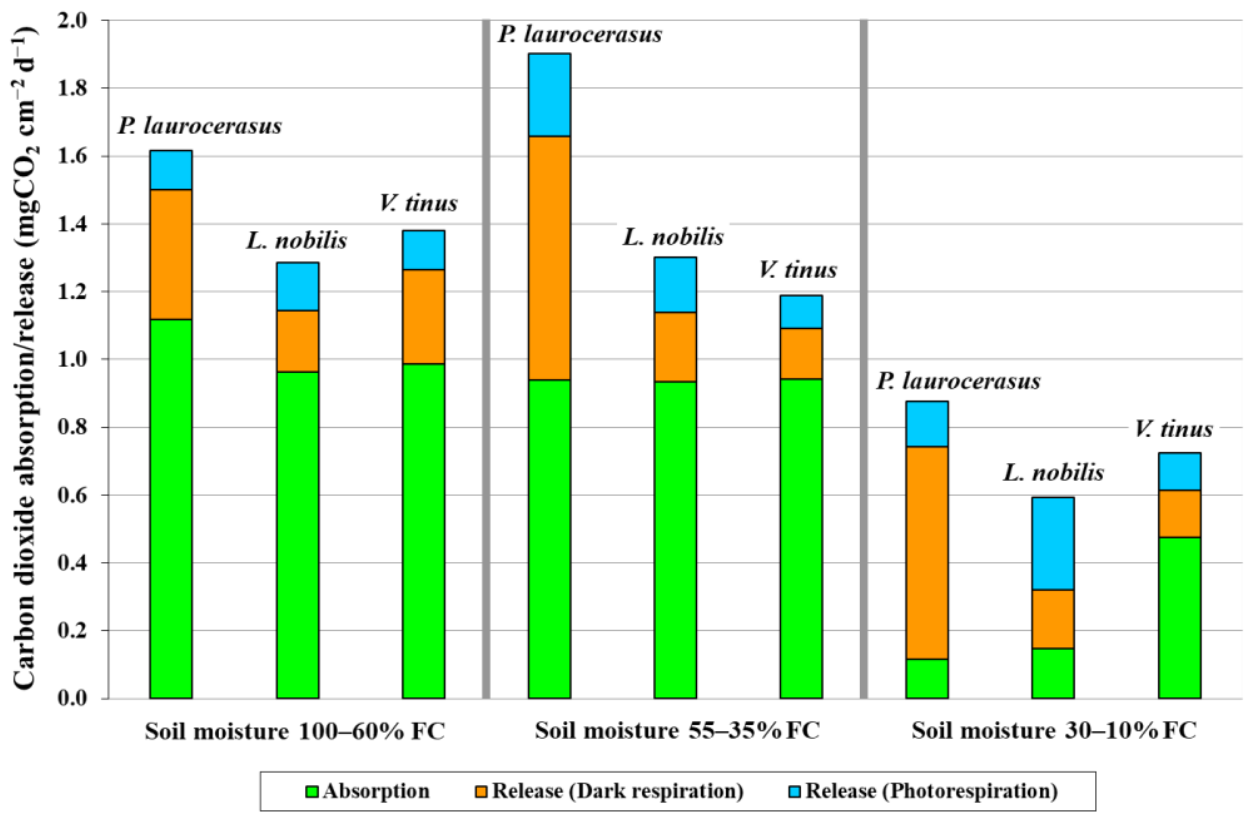

Fig. 2. Carbon dioxide absorption/release per day by Prunus laurocerasus, Laurus nobilis and Viburnum tinus leaves in different soil moisture conditions.

The analysis of the correlation coefficients between the components of $\mathrm{CO}_{2} / \mathrm{H}_{2} \mathrm{O}$-gas exchange leaves of evergreen plants and the environmental parameters showed the presence of both positive and negative statistically highly significant $(\mathrm{p}<0.01)$ dependencies (Table 2).

Table 2. Correlation coefficients between $\mathrm{CO}_{2} / \mathrm{H}_{2} \mathrm{O}$ gas exchanges in leaves of evergreen plants and environmental factors.

\begin{tabular}{|c|c|c|c|c|c|c|c|c|}
\hline \multirow[b]{2}{*}{ Species } & \multirow[b]{2}{*}{$\begin{array}{l}\text { Parameter gas } \\
\text { exchanges }\end{array}$} & \multicolumn{7}{|c|}{ Environmental factor } \\
\hline & & $\begin{array}{c}\text { DLI } \\
\left(\mathrm{mol} \mathrm{m}^{-2}\right. \\
\left.\mathrm{d}^{-1}\right)\end{array}$ & $\begin{array}{c}\mathrm{T} \\
\left({ }^{\circ} \mathrm{C}\right)\end{array}$ & $\begin{array}{l}\mathrm{T}_{\mathrm{MAX}} \\
\left({ }^{\circ} \mathrm{C}\right)\end{array}$ & $\begin{array}{l}\mathrm{T}_{\mathrm{MIN}} \\
\left({ }^{\circ} \mathrm{C}\right)\end{array}$ & $\begin{array}{l}\text { RH } \\
(\%)\end{array}$ & $\begin{array}{l}\text { VPD } \\
(\mathrm{kPa})\end{array}$ & $\begin{array}{c}\mathrm{SM} \\
(\% \mathrm{FC})\end{array}$ \\
\hline \multirow{4}{*}{\begin{tabular}{|l} 
Prunus \\
laurocerasus
\end{tabular}} & $\mathrm{E}\left(\mathrm{mgH}_{2} \mathrm{O} \mathrm{cm}^{-2} \mathrm{~d}^{-1}\right)$ & $0.70^{* *}$ & $0.78 * *$ & $0.68 * *$ & $0.73 * *$ & $-0.68 * *$ & $0.77 * *$ & $-0.25 * *$ \\
\hline & $\mathrm{g}_{\mathrm{S}}\left(\mathrm{mm} \mathrm{s}^{-1}\right)$ & $0.38 *$ & 0.14 & 0.17 & 0.15 & -0.06 & 0.03 & $0.37 *$ \\
\hline & $\mathrm{A}\left(\mathrm{mgCO}_{2} \mathrm{~cm}^{-2} \mathrm{~d}^{-1}\right)$ & 0.12 & -0.22 & -0.12 & -0.22 & 0.17 & -0.31 & $0.63 * *$ \\
\hline & $\mathrm{R}_{\mathrm{RTotal}}\left(\mathrm{mgCO}_{2} \mathrm{~cm}^{-2} \mathrm{~d}^{-1}\right)$ & $0.74 * *$ & $0.85 * *$ & $0.70 * *$ & $0.84 * *$ & $-0.47^{*}$ & $0.73 * *$ & $-0.59 *$ \\
\hline \multirow{4}{*}{$\begin{array}{l}\text { Laurus } \\
\text { nobilis }\end{array}$} & $\mathrm{E}\left(\mathrm{mgH}_{2} \mathrm{O} \mathrm{cm}^{-2} \mathrm{~d}^{-1}\right)$ & $0.42 * *$ & $0.48 * *$ & $0.43 * *$ & $0.44 * *$ & $-0.43 * *$ & $0.52 * *$ & $0.34 * *$ \\
\hline & $\mathrm{g}_{\mathrm{S}}\left(\mathrm{mm} \mathrm{s}^{-1}\right)$ & 0.11 & -0.21 & -0.22 & -0.20 & 0.01 & -0.17 & $0.62 * *$ \\
\hline & $\mathrm{A}\left(\mathrm{mgCO}_{2} \mathrm{~cm}^{-2} \mathrm{~d}^{-1}\right)$ & 0.07 & 0.11 & 0.10 & 0.10 & 0.02 & 0.06 & $0.66 * *$ \\
\hline & $\mathrm{R}_{\mathrm{RTotal}}\left(\mathrm{mgCO}_{2} \mathrm{~cm}^{-2} \mathrm{~d}^{-1}\right)$ & $0.46^{* *}$ & $0.51 * *$ & $0.44 * *$ & $0.56^{* *}$ & -0.12 & $0.37 *$ & $-0.35 *$ \\
\hline \multirow{4}{*}{$\begin{array}{l}\text { Viburnum } \\
\text { tinus }\end{array}$} & $\mathrm{E}\left(\mathrm{mgH}_{2} \mathrm{O} \mathrm{cm}^{-2} \mathrm{~d}^{-1}\right)$ & $0.80 * *$ & $0.87 * *$ & $0.81 * *$ & $0.77 * *$ & $-0.61 * *$ & $0.89 * *$ & $0.46^{* *}$ \\
\hline & $\mathrm{g}_{\mathrm{S}}\left(\mathrm{mm} \mathrm{s}^{-1}\right)$ & $0.46^{* *}$ & $0.50 * *$ & $0.44 * *$ & $0.44 * *$ & $-0.28 *$ & $0.44 * *$ & $0.56^{* *}$ \\
\hline & $\mathrm{A}\left(\mathrm{mgCO}_{2} \mathrm{~cm}^{-2} \mathrm{~d}^{-1}\right)$ & $0.41 * *$ & 0.07 & 0.16 & -0.08 & 0.01 & 0.03 & $0.40 * *$ \\
\hline & $\mathrm{R}_{\mathrm{RTotal}}\left(\mathrm{mgCO}_{2} \mathrm{~cm}^{-2} \mathrm{~d}^{-1}\right)$ & $0.84 * *$ & $0.97 * *$ & $0.89 * *$ & $0.95 * *$ & $-0.59 * *$ & $0.94 * *$ & $0.34 *$ \\
\hline \multicolumn{9}{|c|}{$\begin{array}{l}\text { E - average daily transpiration; } g_{S}-\text { stomatal conductance; } \mathrm{A}-\text { average daily carbon dioxide absorption; } \mathrm{R}_{\mathrm{RTota}} \\
- \text { total carbon dioxide release due to the respiration; DLI - Daily Light Integral; } \mathrm{T}-\text { average daily air } \\
\text { temperature; } \mathrm{T}_{\mathrm{MAX}} \text { - daily maximum air temperature; } \mathrm{T}_{\mathrm{MIN}}-\text { daily minimum air temperature; } \mathrm{RH}-\text { average daily } \\
\text { relative humidity; VPD - vapor pressure deficit; SM - soil moisture; } * \text {, ** represent } \mathrm{p}<0.05 \text { and } \mathrm{p}<0.01 \text {, } \\
\text { respectively. }\end{array}$} \\
\hline
\end{tabular}

In the studied species, a high positive relationship was found between the amount of water released as a result of transpiration, the release of $\mathrm{CO}_{2}$ and environmental factors: the 
DLI, air temperatures and the vapor pressure deficit, and a negative one - with relative air humidity. Low coefficients of pair correlation between the value of stomatal conductivity, absorption of carbon dioxide by Prunus laurocerasus and Laurus nobilis leaves, and environmental parameters: lighting, air temperature and humidity, indicate the absence of a linear relationship (uncorrelated variables), but not the absence of a relationship as such. They suggest the possible independence of these components of the gas exchange of leaves of Prunus laurocerasus, Laurus nobilis and the predominance of fluctuating variability. A statistically significant positive relationship between the amount of $\mathrm{CO}_{2}$ absorbed and water availability was established for all species. Among the studied species, the experimental plants Viburnum tinus were distinguished by the presence of highly significant correlation coefficients between the value of stomatal conductivity and environmental factors (DLI, air temperature and humidity, soil moisture) (Table 2).

Based on experimental data on the amount of daily carbon dioxide absorption and environmental indicators obtained during daily measurements, by step-by-step regression analysis and using the "Nonlinear estimation" procedure of the module "User regression derived function of the loss", the parameters of the regression equations were fitted and optimized. Developed mathematical models provides a forecast of the values the intensity of daily absorption by the unit of the leaf surface area of Prunus laurocerasus, Laurus nobilis and Viburnum tinus plants based on the values of environmental factors: average, minimum and maximum air temperature, Daily Light Integral, vapor pressure deficit and soil moisture. The calculated coefficients of the model parameters are shown in Table 3.

Table 3. Regression equations quantifying of carbon dioxide absorption by evergreen plants responses to environmental.

\begin{tabular}{|c|c|c|c|c|c|}
\hline Species & Fitting equation & $R^{2}$ & $R M S E$ & $S S E$ & $n$ \\
\hline $\begin{array}{l}\text { Prunus } \\
\text { laurocerasus }\end{array}$ & $\begin{array}{l}\mathrm{A}=-5.9626+0.0169 \mathrm{SM}+0.5357 \mathrm{~T}-0.0086 \mathrm{~T}^{2}+ \\
0.0012 \mathrm{DLI}-0.3366 \mathrm{VPD}-0.0829 \mathrm{~T}_{\mathrm{MIN}}\end{array}$ & 0.89 & 0.146 & 0.639 & 30 \\
\hline Laurus nobilis & $\begin{array}{l}\mathrm{A}=0.0425 \mathrm{SM}-0.0002 \mathrm{SM}^{2}-0.3656 \mathrm{~T}+ \\
0.0079 \mathrm{~T}^{2}+0.0067 \mathrm{DLI}-0.076 \mathrm{VPD}^{2}-0.007 \mathrm{~T}_{\mathrm{MIN}} \\
+0.312 \mathrm{~T}_{\mathrm{MIN}}\end{array}$ & 0.84 & 0.174 & 1.701 & 56 \\
\hline Viburnum tinus & $\begin{array}{l}\mathrm{A}=4.7368+0.0364 \mathrm{SM}-0.0003 \mathrm{SM}^{2}-0.4648 \mathrm{~T} \\
+0.0111 \mathrm{~T}^{2}+0.0415 \mathrm{DLI}-0.2783 \mathrm{VPD}^{2}- \\
0.0121 \mathrm{~T}_{\mathrm{MAX}}\end{array}$ & 0.84 & 0.137 & 1.065 & 57 \\
\hline \multicolumn{6}{|c|}{$\begin{array}{l}\text { A - average daily carbon dioxide absorption, } \mathrm{mgCO}_{2} \mathrm{~cm}^{-2} \mathrm{~d}^{-1} ; \mathrm{SM}-\text { soil moisture, } \% \mathrm{FC} ; \mathrm{T}-\text { average daily } \\
\text { air temperature, }{ }^{\circ} \mathrm{C} \text {; DLI - Daily Light Integral, mol m} \mathrm{m}^{-2} \mathrm{~d}^{-1} ; \mathrm{VPD}-\text { vapor pressure deficit, } \mathrm{kPa} \text {; } \mathrm{T}_{\mathrm{MIN}}-\text { daily } \\
\text { minimum air temperature, }{ }^{\circ} \mathrm{C} ; \mathrm{T}_{\mathrm{MAX}}-\text { daily maximum air temperature, }{ }^{\circ} \mathrm{C} ; R^{2}-\text { determination coefficients; } \\
S S E \text { - error sum of squares; } n \text { - number of observations for model development and evaluation. }\end{array}$} \\
\hline
\end{tabular}

When studying the carbon dioxide gas exchange of woody plants, one of the main tasks was to obtain a quantitative characterization of the relationship between the daily absorption of carbon dioxide and environmental conditions, which allows us to assess the role of plants in the carbon balance of an urban ecosystem.

The evaluation of the quality of the models based on the three basic criteria $\mathrm{R}^{2}$, RMSE and SSE showed that the developed regression models are quite adequate, since the total losses estimated by the loss minimization function are small, the RMSE of the forecast when calculated using these equations is $0.146-0174 \mathrm{mgCO}_{2} \mathrm{~cm}^{-2} \mathrm{~d}^{-1}$, and the value of the determination coefficients is within $0.84-0.89$.

The calculated from equations values and measured amounts of carbon dioxide absorbed per day by unit area of the leaf blade $\left(1 \mathrm{~cm}^{2}\right)$ of Prunus laurocerasus, Laurus nobilis, and Viburnum tinus for all days of measurements, including different environmental conditions, are shown in Figures 3-5 in the form of combined graphs. As can be seen from the figures, the calculated data and the experimental data are close. 


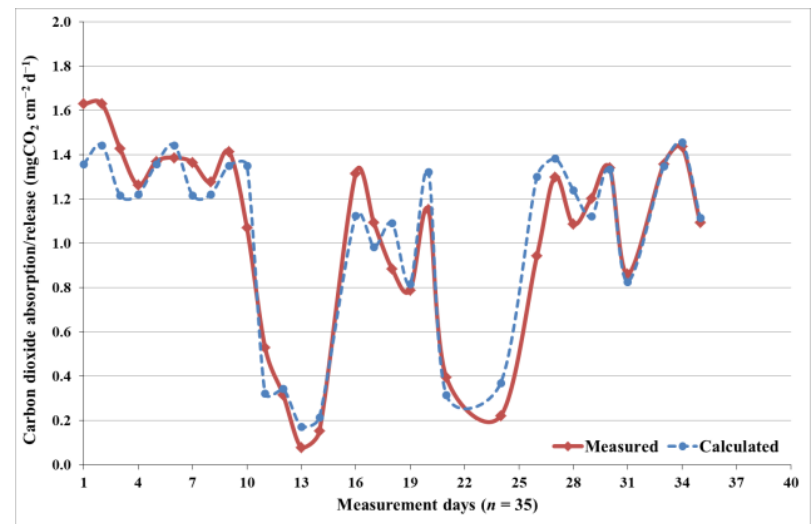

Fig. 3. Comparison of observed vs. predicted quantity of daily carbon dioxide absorption by leaves Prunus laurocerasus to differing environmental conditions.

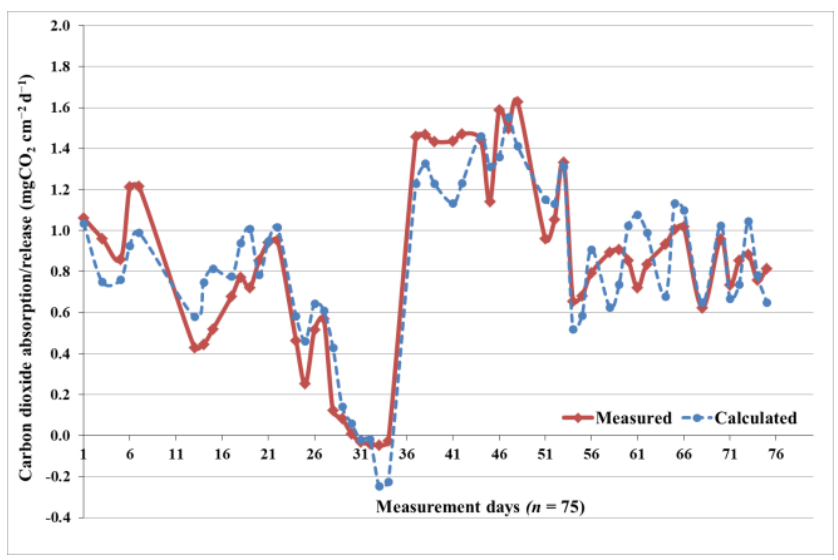

Fig. 4. Comparison of observed vs. predicted quantity of daily carbon dioxide absorption by leaves Laurus nobilis to differing environmental conditions.

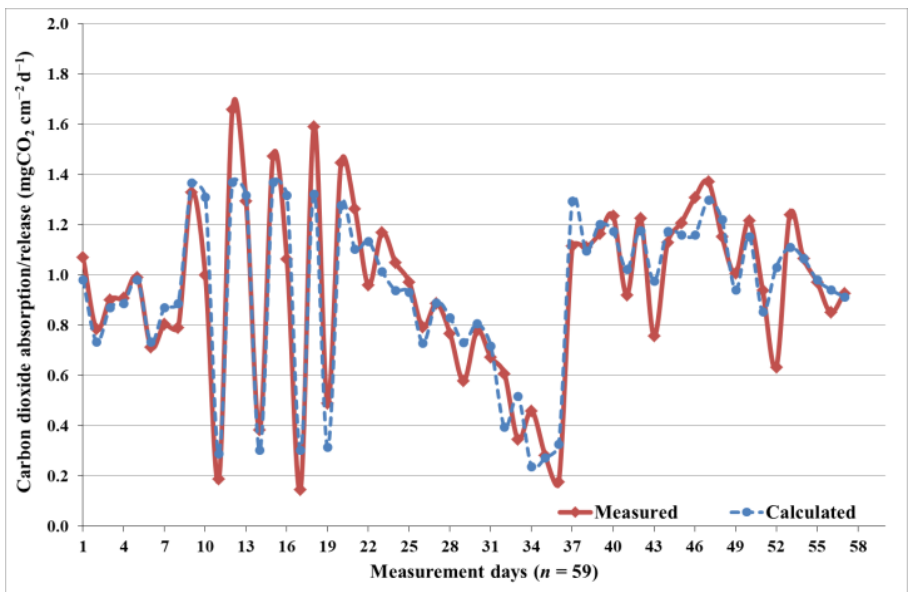

Fig. 5. Comparison of observed vs. predicted quantity of daily carbon dioxide absorption by leaves Viburnum tinus to differing environmental conditions. 


\section{Conclusion}

The study showed that water availability is the main inhibitor of carbon dioxide gas exchange of Prunus laurocerasus, Laurus nobilis and Viburnum tinus during their growing season. The greatest resistance to drought and the ability to absorb $\mathrm{CO}_{2}$ under hydrothermal stress was found in Viburnum tinus, whose positive carbon gas exchange was 2 times bigger in severe water deficit. Quantitative indicators of the daily absorption of carbon dioxide by a unit of leaf surface area under various environmental conditions are determined. The maximum average daily amount of $\mathrm{CO}_{2}$ absorbed by Prunus laurocerasus leaves was observed in June $\left(1.38 \mathrm{mgCO}_{2} \mathrm{~cm}^{-2} \mathrm{~d}^{-1}\right)$ and in September $(1.30$ $\left.\mathrm{mgCO}_{2} \mathrm{~cm}^{-2} \mathrm{~d}^{-1}\right)$, Viburnum tinus - in August $\left(1.17 \mathrm{mgCO}_{2} \mathrm{~cm}^{-2} \mathrm{~d}^{-1}\right)$. The seasonal dynamics of carbon dioxide absorption by Laurus nobilis leaves showed slight fluctuations with a maximum in July $\left(0.93 \mathrm{mgCO}_{2} \mathrm{~cm}^{-2} \mathrm{~d}^{-1}\right)$. For all species, there was a natural decrease in assimilation activity with the attenuation of growth processes in autumn.

The share of respiratory expenses in the hot summer period can increase in Prunus laurocerasus to 27.6-53.5\%, in Laurus nobilis - to 30.7-40.6\%, in Viburnum tinus - to $47.9 \%$, in other months-does not exceed $14-26 \%$. Under optimal environmental conditions the ratios of photosynthesis and respiration processes are on average $21.9 \%$ (Prunus laurocerasus), 12.8\% (Laurus nobilis), and 12.0\% (Viburnum tinus).

The threshold value in conditions of increasing water deficit is a decrease in soil moisture below 35\% FC. Species-specific features of the response of introduced plant species to drought are manifested when the soil moisture is below $30 \%$ FC. Under effect of severe drought the amount of $\mathrm{CO}_{2}$ absorbed by Prunus laurocerasus leaves is reduced by 10 times, Laurus nobilis - by 7 times, Viburnum tinus - by 2 times. With a strong water deficit, negative carbon gas exchange possible in Laurus nobilis. The ability of the stomatal apparatus of Viburnum tinus to maintain the stomata in an open or closed state, depending on the prevailing hydrothermal conditions, provides a high adaptive ability of this plant to drought.

The total respiration values of the leaves were in direct linear dependence on the illumination and air temperature. The positive carbon dioxide gas exchange of Prunus laurocerasus, Laurus nobilis and Viburnum tinus and the carbon dioxide absorption exceeding the respiration level during the growing season by $1-5.1,1.5-3.7$ and 1.1-6.2 times, respectively, indicate the significant role of the studied introduced plant species in the optimization of urban ecosystems in the southern regions of Russia.

The regularities of the species-specific response of the photosynthetic activity of Prunus laurocerasus, Laurus nobilis, and Viburnum tinus to the impact of the environment during the growing season are revealed, and predictive models are fitting to quantify plants ability to absorb carbon dioxide under the prevailing environmental conditions.

The accumulation of such data, which describes plant responses at different levels of organization, allows us to give a more complete picture of the adaptation of species to the environment, including anthropogenic factors, and to predict their behavior in the conditions of climate change.

\section{References}

1. J.A. Salmond, M. Tadaki, S. Vardoulakis, K. Arbuthnott, A. Coutts, M. Demuzere, K.N. Dirks, C. Heaviside, Sh. Lim, H. Macintyre, et al, Environ. Health, 15, S36 (2016)

2. C. Stefano, R.F. Rallo, S. Ulgiati, Ecol. Model., 360, 328 (2017) 
3. M. Braubach, A. Egorov, P. Mudu, T. Wolf, C.W. Thompson, M. Martuzzi, NatureBased Solutions to Climate Change Adaptation in Urban Areas Theory and Practice of Urban Sustainability Transitions, 187 (2017)

4. F. Aram, E.H. García, E. Solgi, S. Mansournia, Heliyon, 5(4), 1339 (2019)

5. Y.V. Plugatar, Z.K. Klymenko, I.V. Ulanovskaya, V.K. Zykova, S.A. Plugatar, Acta Hortic, 1240, 65 (2019)

6. A.K. Yuzbekov, W. Zuxun, Moscow University Bulletin. Series 16. Biology, 74(4), 321 (2019)

7. P. Tor-ngern, N. Leksungnoen, BMC Ecol, 20, 20 (2020)

8. S.P. Korsakova, Yu.V. Plugatar, O.A. Ilnitsky, M. Karpukhin, Agronomy Research, 17(2), 518 (2019)

9. A. Pashtetsky, Y.V. Plugatar, O. Ilnitsky, S. Korsakova, Acta Hortic., 1263, 199 (2019)

10. S. von Caemmerer, Plant Cell Environ., 36(9), 1617 (2013)

11. V.K. Bolondinskii, L.M. Vilikainen, V.B. Pridacha, T.A. Sasonova, Transactions of the Karelian Research Centre of the Russian Academy of Sciences, 3, 20 (2020)

12. V.V. Efimov, E.M. Volodin, A.E. Anisimov, Physical Oceanography, 2, 3 (2015)

13. S.P. Korsakova, Yu.V. Plugatar, O.A. Ilnitsky, E.I. Kleiman, South of Russia: ecology, development, 13(1), 101 (2018)

14. J.E. Faust, V. Holcombe, N.C. Rajapakse, D.R. Layne, American Society for Agriculture Research, 40(3), 645 (2005)

15. Yu.V. Plugatar, S.P. Korsakova, M.S. Kovalev, Bull. of the State Nikita Botan. Gard., 135, 9 (2020) 